\title{
Pleomorphic Adenoma of Parotid Gland
}

\author{
Anil M Shinde ${ }^{1}$, Rajwardhan A Shinde ${ }^{2}$ and Himanshu Soni ${ }^{3 *}$ \\ ${ }^{1}$ Consultant General Surgeon, Satara Hospital and Diagnostic Centre, Maharashtra, \\ India \\ ${ }^{2}$ Consultant Oral and Maxillofacial Surgeon Satara Hospital and Diagnostic Centre, \\ Maharashtra, India \\ ${ }^{3}$ Oral and Maxillofacial Surgeon, Fellowship in Cranio-Maxillo-Facial Trauma \\ Surgery - AOMSI Fellow in Head and Neck Surgical Oncology - FHNO Mahatma \\ Gandhi Cancer Hospital, Maharashtra, India \\ *Corresponding Author: Himanshu Soni, Oral and Maxillofacial Surgeon, \\ Fellowship in Cranio-Maxillo-Facial Trauma Surgery - AOMSI Fellow in Head and \\ Neck Surgical Oncology - FHNO Mahatma Gandhi Cancer Hospital, Maharashtra, \\ India.
}

\begin{abstract}
Pleomorphic Adenoma is most common benign neoplasm of the major and minor salivary glands. It is predominantly affect the superficial lobe of the parotid gland. Pleomorphic adenoma is an asymptomatic swelling which gradually increases in size if not treated. The neoplasm has a female predilection between 30-60 years of age. The aim of this case report is to discuss clinical manifestation, diagnosis and treatment plan of pleomorphic adenoma of the parotid gland. A case of pleomorphic adenoma in an 46 years old male, who presented with asymptomatic firm fluctuant swelling in right pre-auricular region. The lesion was examined clinical, histopathological and investigations were carried out. FNAC showed benign salivary gland elements consistent with pleomorphic adenoma. Superficial parotidectomy was done with adjacent free margins, taking care not to injury the branches of facial nerve. Post recovery was uneventful with no defect of facial nerve function. This case report highlights the need for proper diagnosis and treatment plan in the cases of benign tumours.
\end{abstract}

Keywords: Pleomorphic Adenoma; Salivary Gland Neoplasm; Superficial Parotidectomy; Facial Nerve

\section{Introduction}

Pleomorphic adenoma is most common benign tumour of salivary gland, it's also known as a benign mixed tumour, pleomorphic adenoma constitutes up to two thirds of all salivary gland tumours [1]. Pleomorphic adenoma is most commonly affected the parotid gland (85\%) and in most of cases parotid tumours affect superficial lobe of gland than deep lobe of gland $[2,3]$.
Received: September 01, 2021

Published: September 23, 2021

(C) All rights are reserved by Himanshu Soni., et al. 
treated by superficial parotidectomy with preservation of facial nerve.

\section{Case Report}

46 years old male patient reported with a chief complaint of slow growing asymptomatic swelling on right side of face since 1 year. The swelling was painless and initially small in size and had gradually increased with time to its current size. His past medical, surgical, social and family history was non-contributory. On physical examination revealed a facial asymmetry. A well-defined, firm, fluctuant swelling, $6 * 8 \mathrm{~cm}$ in size seen on right side of the face. The right ear lobule was elevated (Figure 1). Function of facial nerve was intact and no lymphadenopathy was present. Routine blood test findings were within normal limits.

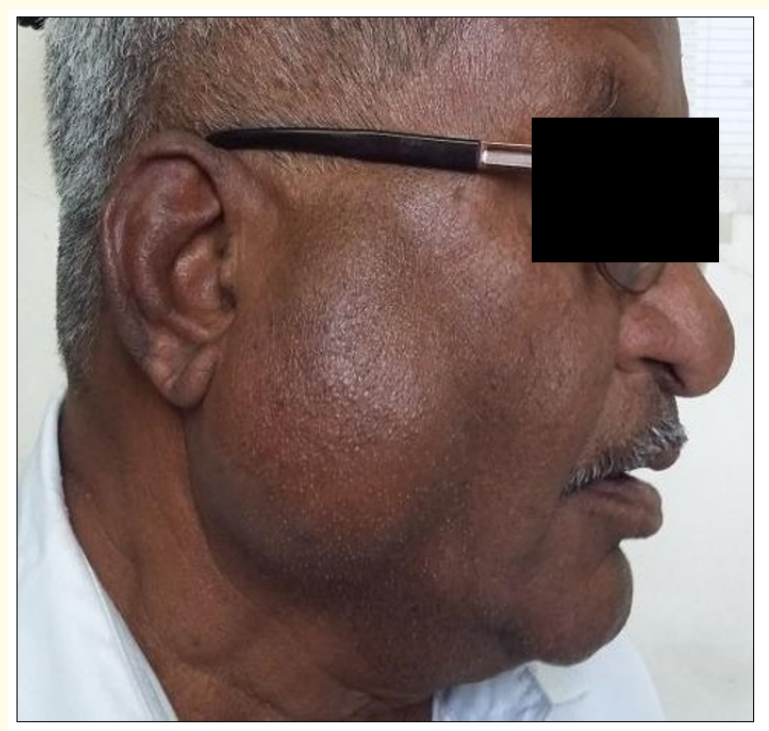

Figure 1: Tumour mass on right preauricular region.

Findings on fine-needle aspirations were showed admixed epithelial, myoepithelial and mesenchymal tissue elements.

After obtaining appropriate consent, patient was posted for a left superficial parotidectomy.

\section{Procedure}

Anaesthesia- Nasal endotracheal intubation was done under general anaesthesia. 1\% lidocaine with 1:80,000 adrenaline has been injected subcutaneously throughout the entire field of operation. Incision- A modified blair's incision was taken in preauricular skin crease and extending inferiorly through the skin and plastyma. The skin flap was raised under periparotid fascia. Blunt dissection was done with haemostat in retrograde manner in order to prevent injury to branches of facial nerve (Figure 2).

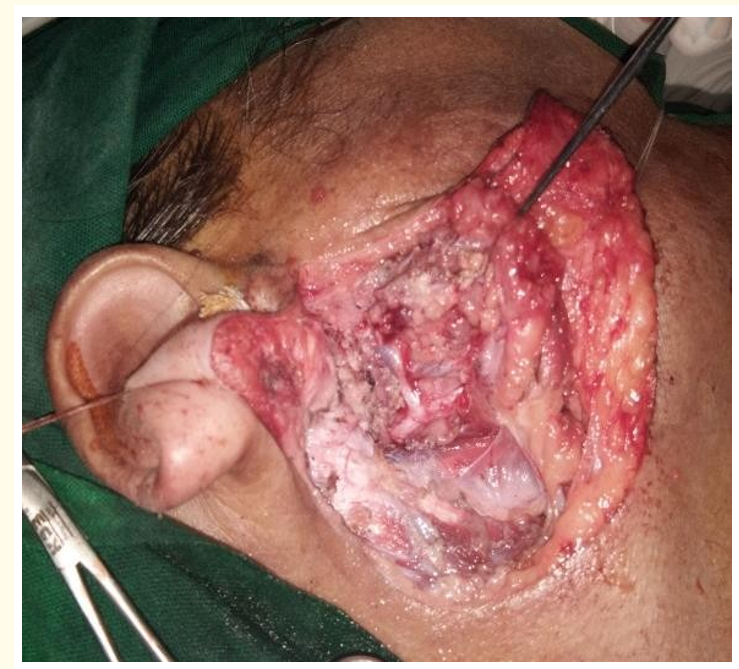

Figure 2: Incision and dissection of facial nerve.

Dissection of facial nerve and resection of the gland- Posterior belly of digastric and tragal pointer were used as landmark for identification of main trunk of facial nerve. After identification of main trunk of facial nerve dissection was carried with fine haemostat to create a tunnel in tissue immediately above the nerve. Care was taken to avoid inadvertent entry into the tumour while preservation terminal branches of facial nerve. The superficial lobe of parotid gland was excised with tumour and terminal branches of facial nerve preserved (Figure 3). The excised tumour mass was sent for histopathological examination (Figure 4). Histopathology revealed the characteristic features of a pleomorphic adenoma with admixture of all components: epithelial, myoepithelial and mesenchymal (Figure 5).

After excision of tumour, wound was irrigated with betadine and saline solution and integrity of the facial nerve was checked. After achieving haemostasis wound was closed in layers. 


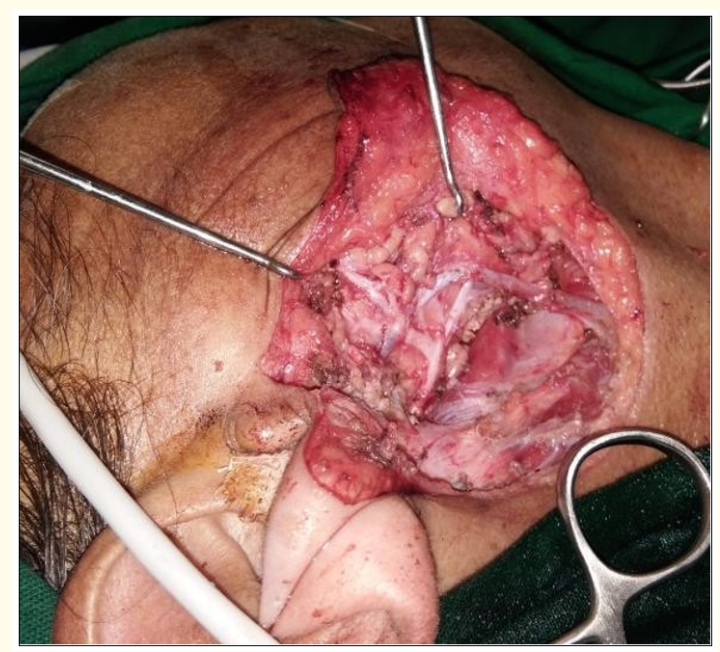

Figure 3: Superficial parotidectomy with preservation of facial nerve.

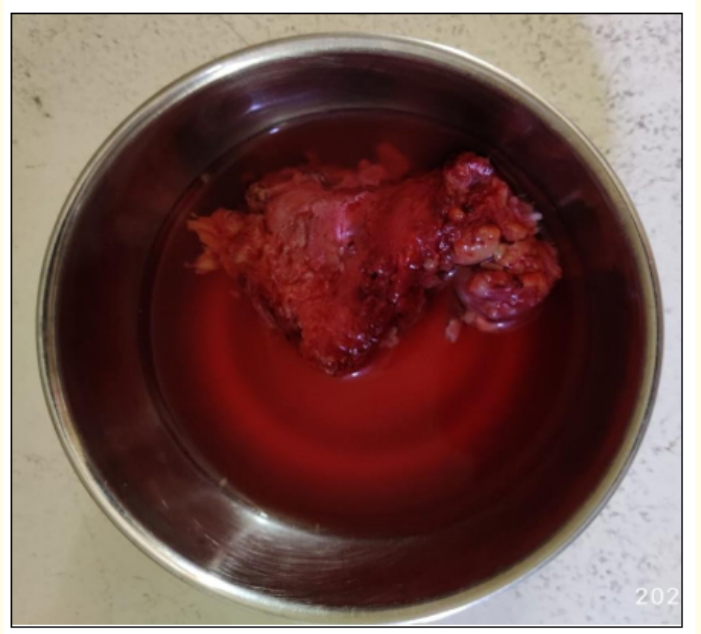

Figure 4: Tumour specimen.

Closed suction drainage with external pressure by gauze was maintained for 72 hours. The sutures were removed 10 days after surgery. After a 1 year follow up, prognosis was excellent and no signs of recurrences were observed under periodic review.

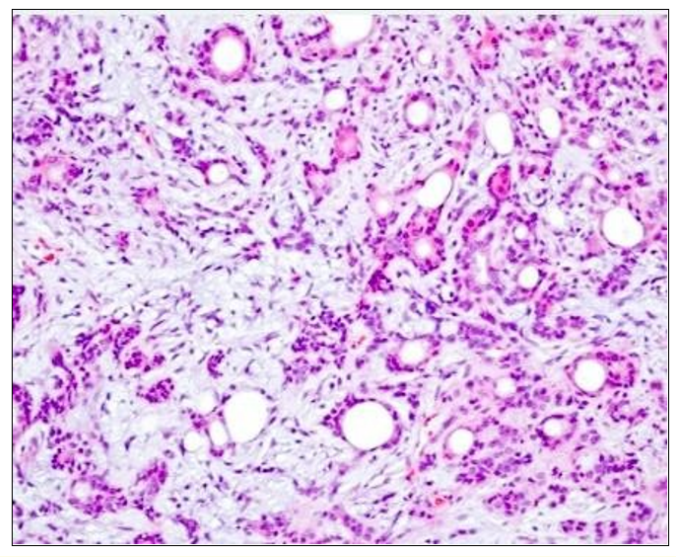

Figure 5: Histopathological image of pleomorphic adenoma of parotid gland.

\section{Discussion}

According to WHO (1972) pleomorphic adenoma defined as well defined salivary neoplasm characterized by its pleomorphic or mixed appearance and it has three components: an epithelial component, myoepithelial component, and mesenchymal component $[7,8]$. Pleomorphic adenoma found any age group range of 13 - 80 years with an average of 46 years and slightly female predilection [9]. Our patient was 46 years old male patient who presented with slowly growing painless swelling on right side of preauricular region since 1 year. On clinical examination pleomorphic adenoma is slowly growing well defined, asymptomatic, firm and mobile mass without ulceration of overlying mucosa [10]. Parotid tumours usually located below the lobule of ear and overlying angle of mandible. Paralysis of facial nerve is uncommon with most of parotid tumours although untreated tumours may present with facial nerve paralysis $[11,14]$. In our case report, function of facial nerve was intact pre-operatively.

To assess the salivary gland diseases, various imaging modalities used such as ultrasonography, FNAC, CT scan and MRI scan. The selection of imaging modalities depends on clinical feature of pathology, local protocol and site of suspected pathology. Ultrasound is quick and economical and non-invasive imaging modality is choice for assessment of salivary gland diseases [12]. In present study FNAC was done and report confirmed tumour of parotid gland. 
The treatment of pleomorphic adenoma is surgical resection and resection can be done with enucleation, superficial parotidectomy and total parotidectomy depends upon extent of tumour. Recurrence rate is low in total parotidectomy as compare to enucleation and superficial parotidectomy. Recurrence rate of pleomorphic adenoma is around 0.5 to $10 \%$ after the surgical management [13]. In present case, superficial parotidectomy with tumour was excised with care to preserve the facial nerve branches. The patient in current case was followed up for a period of 1 year and there was no sign of recurrences and function of facial nerve was intact.

\section{Conclusion}

Pleomorphic adenoma, although a benign tumour of salivary gland, have to be recognized at an early stage and surgically resected. Being benign in nature, it should be proper diagnosis and careful surgically resected preserving the facial nerve will aid in adequate treatment with less chances of recurrence.

\section{Bibliography}

1. Califano J and Eisele DW. "Benign salivary gland neoplasms". Otolaryngologic clinics of North America 32.5 (1999): 861-873.

2. Pilch BZ. "Head and neck surgical pathology". Lippincott Williams and Wilkins (2001).

3. Ungari C., et al. "Parotid glands tumours: overview of a 10-year experience with 282 patients, focusing on 231 benign epithelial neoplasms". European Review for Medical and Pharmacological Sciences 12.5 (2008): 321-325.

4. Neville Brad W. "Oral and Maxillofacial Pathology" $\left(3^{\text {rd }}\right.$ edition): 477-479.

5. Sergi B., et al. "Giant deep lobe parotid gland pleomorphic adenoma involving the parapharyngeal space. Report of three cases and review of the diagnostic and therapeutic approaches". Acta Otorhinolaryngologica Italica 28.5 (2008): 261.

6. Aggarwal A., et al. "Pleomorphic adenoma of minor salivary gland: a case report”. RSBO Revista Sul-Brasileira de Odontologia 9.1 (2012): 97-101.

7. Kondo T. "A case of lipomatous pleomorphic adenoma in the parotid gland: a case report". Diagnostic Pathology 4.1 (2009): $1-3$.
8. Traiger J and Rosen MB. "Mixed tumor of the cheek: report of a case". Oral Surgery, Oral Medicine, Oral Pathology 19.6 (1965): 711-714.

9. Van Der Wal JE., et al. "Histological reclassification of 101 intraoral salivary gland tumours (new WHO classification)". Journal of Clinical Pathology 45.9 (1992): 834-835.

10. Dalati T and Hussein MR. "Juvenile pleomorphic adenoma of the cheek: a case report and review of literature". Diagnostic Pathology 4.1 (2009): 1-5.

11. Da Silva SJ., et al. "Metachronous bilateral pleomorphic adenoma of the parotid gland". Oral surgery, Oral Medicine, Oral Pathology, Oral Radiology, and Endodontology 101.3 (2006): 333-338.

12. Thoeny HC. "Imaging of salivary gland tumours". Cancer Imaging 7.1 (2007): 52.

13. Friedrich RE., et al. "Pleomorphic adenoma of the salivary glands: analysis of 94 patients". Anticancer Research 25.3 (2005): 1703-1705.

14. Takahama A., et al. "Giant pleomorphic adenoma of the parotid gland". Medicina Oral Patologia Oral Y Cirugia Bucal (2008).

Volume 3 Issue 10 October 2021

(C) All rights are reserved by Himanshu Soni., et al. 